\title{
Laryngeal Measurements and Diagnostic Tools for Diag- nosis of Chronic Obstructive Pulmonary Disease
}

Verónica Casado, MD, PbD

Sandra M. Navarro, MD

Andrés E. Alvarez, MD

Mercedes Villafañe, MD

Ana Miranda, MD

Natalia Spaans, MD

Representing the Researcb Group ParquEPOC

Parquesol Teaching Health Center, West Valladolid Multiprofessional Family and Communitary Care Teaching Unit, Valladolid, Spain

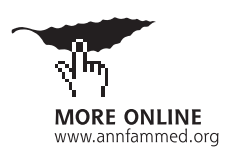

Conflicts of interest: authors report none.

\section{CORRESPONDING AUTHOR}

Verónica Casado, MD, PhD

Centro de Salud Universitario Parquesol Avenida Ciudad de la Habana, 17 47014 Valladolid, Spain veronica.casado@telefonica.net

\begin{abstract}
PURPOSE The purpose of this study was to evaluate sensitivity, specificity, and positive and negative likelihood ratios of laryngeal height, lung function, and diagnostic questionnaires for screening and diagnosis of chronic obstructive pulmonary disease (COPD).
\end{abstract}

METHODS We undertook a cross-sectional study of 233 people aged between 40 and 75 years. Measured variables were age, sex, weight, height, body mass index, tobacco use, maximum laryngeal height, and spirometry, and we administered a COPD questionnaire and the Lung Function Questionnaire.

RESULTS For laryngeal height, we found a positive likelihood ratio of 5.21, and for the Lung Function Questionnaire, we found a negative likelihood ratio of 0.10. Combining a maximum laryngeal height of $\leq 4 \mathrm{~cm}$ with Lung Function Questionnaire findings of $\leq 18$ yielded a positive likelihood ratio of 29.06 , and a negative likelihood ratio of 0.26 .

CONCLUSIONS The intrinsic validity of the lung function questionnaire makes it useful for screening. Combining Lung Function Questionnaire results and laryngeal height can help confirm or dismiss COPD.

Ann Fam Med 2015;13:49-52. doi: 10.1370/afm.1733.

\section{INTRODUCTION}

J $\mathrm{n}$ addition to having a major socioeconomic impact, ${ }^{1}$ chronic obstructive pulmonary disease (COPD) is associated with high morbidity and high mortality. Various symptoms and exploratory signs of COPD have been studied, ${ }^{2,3}$ but findings from a physical examination are rarely diagnostic. ${ }^{4}$ Questionnaires, such as a COPD diagnostic questionnaire ${ }^{5,6}$ (which addresses allergies and lower respiratory track symptoms, as well as cough, age, smoking pack-year, body mass index) and the Lung Function Questionnaire ${ }^{7}$ (which addresses age, smoking history, frequency of productive cough, chest sounds, and breathing difficulty during physical activity), have been proposed to select individuals for spirometry because of their validity and simple application in family medicine practice. In 2000 laryngeal height began to be evaluated as a diagnostic sign ${ }^{8}$ without much continuity. ${ }^{9}$ Because sternal elevation produced by the thoracic hyperinsufflation found in this disease is thought to decrease laryngeal and tracheal heights, laryngeal height, tracheal height, and laryngeal descent are also thought to be diagnostic signs of COPD.

Although the validity of examinations that facilitate screening and diagnosis has demonstrated their usefulness, research on exploratory tests is scarce. Our objective was to evaluate the sensitivity, specificity, and positive and negative likelihood ratios of maximum laryngeal height, the Lung Function Questionnaire, and the COPD diagnostic questionnaire for screening and diagnosis in a primary health care population. For this study, we used the maximum laryngeal height, measured from the suprasternal notch to the top of thyroid cartilage at the end of an expiration, as proposed by Strauss and colleagues. ${ }^{8,9}$ 


\section{METHODS}

A cross-sectional investigational study was conducted using a random sampling of a general population aged between 40 to 75 years in a basic health area of 26,108 inhabitants in Valladolid, Spain. Based on an estimated prevalence of COPD in the population, ${ }^{6,7}$ the study sample was calculated to be 200 study participants plus 30\% to account for losses (260 individuals). Of those approached, 233 agreed to participate, signed an informed consent form, and remained enrolled throughout the entire study (June 2012 to June 2014). Any loss of data was due to lack of time. All tests were performed on every participant on the same day. Sixteen researchers were divided into 6 teams of 2 to 3 members, and each team measured the same variables: age, sex, weight, height, body mass index, tobacco use, maximum laryngeal height (measured from the suprasternal notch to the top of thyroid cartilage at the end of an expiration, Figure 1), and spirometry (using the Global Strategy for the Diagnosis, Management and Prevention of COPD, Global Initiative for Chronic Obstructive Lung Disease (GOLD) 2014 criteria as a reference standard ${ }^{10}$ for the diagnosis of COPD); they also administered a COPD questionnaire and a Lung Function Questionnaire. A standardized basal spirometry measurement was performed on each participant. If results showed an obstructive pattern, we performed a bronchodilator test (confirmed by spirometry after inhaled salbutamol, $0.4 \mathrm{mg}$ ). The ratio of FEV1/FVC (forced expiratory volume in 1 second/ forced vital capacity) of $<0.7$ is a marker of airway obstruction and thus diagnostic for COPD.

Because of possible variations in the researchers' findings even with training, we measured the interobserver $\kappa$ index of the research teams for laryngeal height $(0.80 ; 95 \% \mathrm{CI}, 0.68-0.91)$ and spirometry $(0.78 ; 95 \% \mathrm{CI}$, 0.66-0.89). We performed univariate and bivariate analyses of sensitivity, specificity, and positive and negative likelihood ratios.

This study was reviewed and approved by the Research Commission of West Valladolid Primary Care Direction and by the Clinical Research Ethics Committee for the West Valladolid Health Area.

\section{RESULTS}

The mean age of the study participants was 53.7 (SD 7.6) years, and $57.9 \%$ were female (Table 1 ). COPD prevalence was $6 \%$ (64.3\% were male $; 72.8 \%$ had mild to moderate COPD), tobacco use was $18.4 \%$. Maximum laryngeal height was $\leq 4 \mathrm{~cm}$ in $4.5 \%$ of participants. Maximum laryngeal height differences between men and women with and without COPD are statistically significant $(P<.001)$. The sensitivity of maximum laryngeal height and the COPD questionnaire was low, but the specificity for each was high (Table 2). The sensitivity of the Lung Function Questionnaire was high. The positive likelihood ratio was 5.21 for maximum laryngeal height and the negative likelihood ratio was 0.1 for the Lung Function Questionnaire. A combined presence of the Lung Function Questionnaire score of $\leq 18$ (with lower scores indicating a higher probability of COPD) with maximum laryngeal height $\leq 4 \mathrm{~cm}$ yielded a sensitivity of $75 \%$, a specificity of $97 \%$, a positive likelihood ratio of 29.06 , and a negative likelihood ratio of 0.26 .

The probability of suffering from COPD for our population was $61 \%$ if laryngeal height was $\leq 4 \mathrm{~cm}$ and the Lung Function Questionnaire score was $\leq 18$. When a clinical pre-examination suspicion of COPD is $50 \%$,

\section{Figure 1. Measurement points for laryngeal height.}

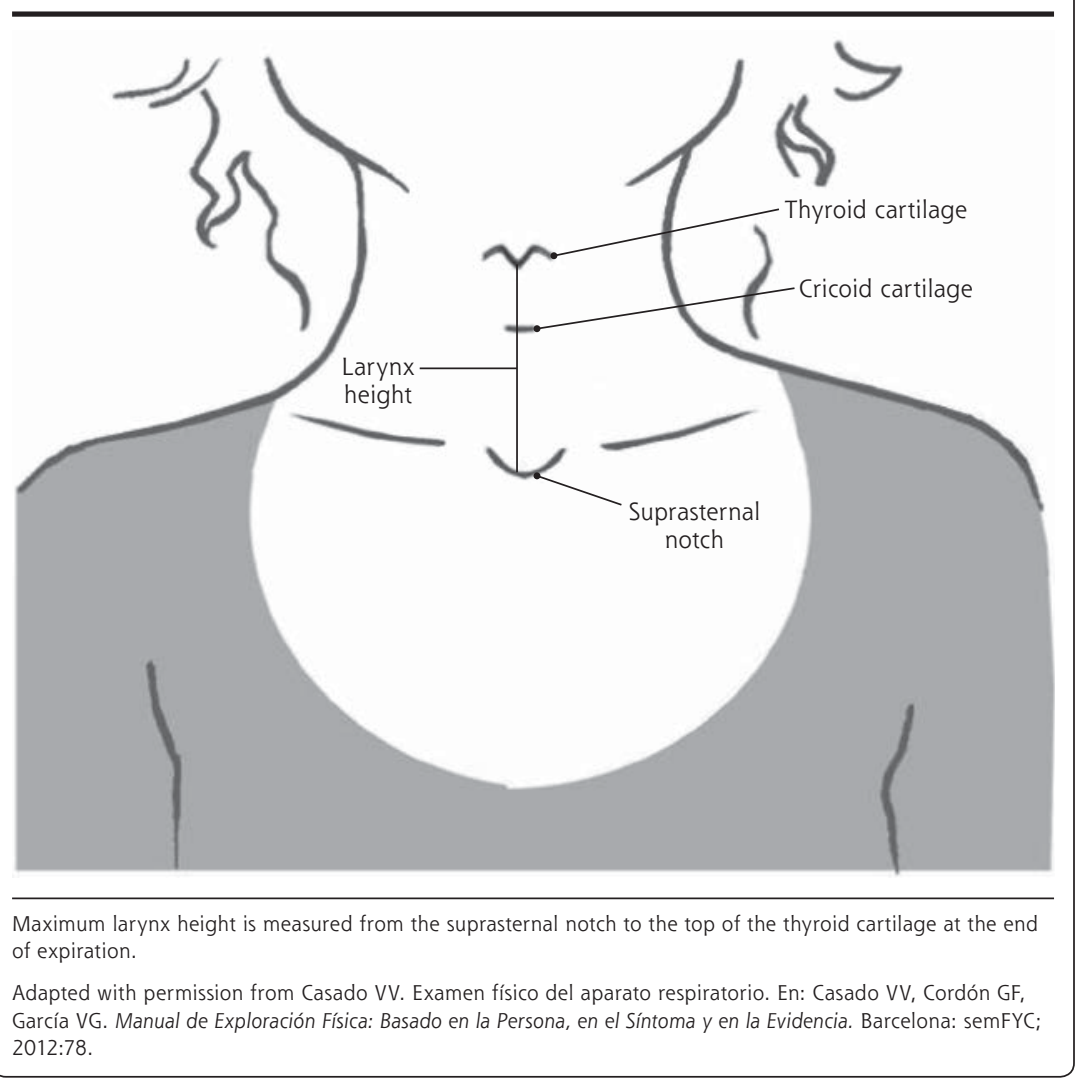




\section{Table 1. Characteristics of Study Participants}

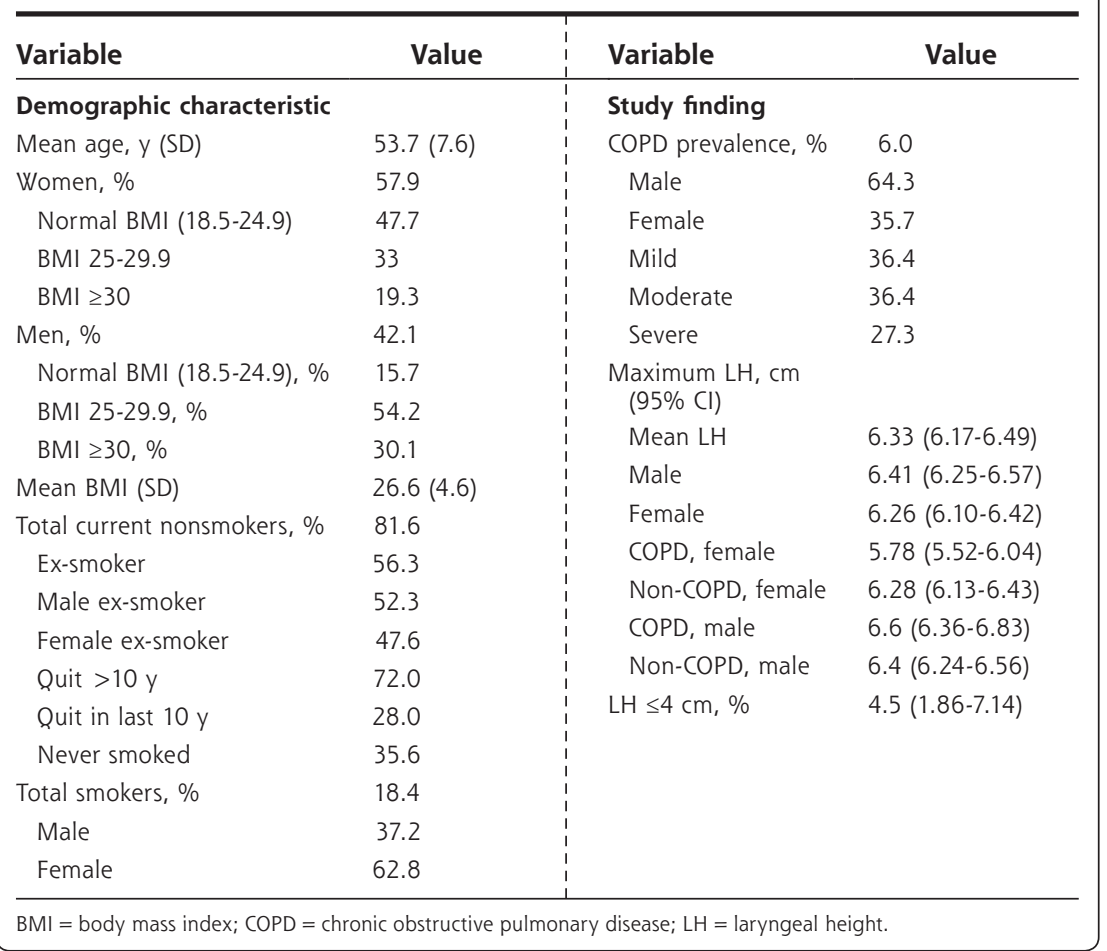

Table 2. Intrinsic Validity and Likelihood Ratios of Laryngeal Height, Lung Function Questionnaire, and COPD Diagnostic Questionnaire

\begin{tabular}{|c|c|c|c|c|}
\hline Measurement & $\begin{array}{c}\text { Sensitivity \% } \\
\text { (Cl 95\%) }\end{array}$ & $\begin{array}{l}\text { Specificity \% } \\
\text { (Cl 95\%) }\end{array}$ & LR+ $(95 \% \mathrm{CI})$ & LR- $(95 \% \mathrm{CI})$ \\
\hline LH & $21(0-43)$ & $969(3-99)$ & $5.21(1.59-17.14)$ & $0.82(0.62-1.08)$ \\
\hline $\mathrm{LH}^{\mathrm{a}}$ & $18(5-41)$ & 96 (94-99) & $4.98(1.2-20.72)$ & $0.85(0.64-1.12)$ \\
\hline LFQ & $93(79-106)$ & $71(65-77)$ & $3.18(0.65-4.09)$ & $0.10(0.02-0.67)$ \\
\hline $\mathrm{LFQ}^{\mathrm{a}}$ & $91(74-108)$ & $70(65-77)$ & $3.11(2.36-4.11)$ & $0.13(0.02-0.83)$ \\
\hline COPD DQ & $36(11-61)$ & $93(89-96)$ & $4.89(2.1-11.4)$ & $0.69(0.47-1.03)$ \\
\hline COPD DQ & $18(5-41)$ & $93(89-96)$ & $2.49(0.62-9.5)$ & $0.88(0.67-0.17)$ \\
\hline $\mathrm{LH}+\mathrm{LFQ}$ & $75(33-117)$ & $97(95-100)$ & $29.06(9.48-89.13)$ & $0.26(0.05-1.4)$ \\
\hline \multicolumn{5}{|c|}{$\begin{array}{l}\mathrm{COPD}=\text { chronic obstructive pulmonary disease } ; \mathrm{DQ}=\text { diagnostic questionnaire; } \mathrm{FEC}=\text { forced vital capac- } \\
\text { ity; } \mathrm{FEV} 1=\text { forced expiratory volume in } 1 \text { second; } \mathrm{LFQ}=\text { Lung Function Questionnaire; } \mathrm{LH}=\text { laryngeal height; } \\
\mathrm{LR}-=\text { negative likelihood ratio; } \mathrm{LR}+=\text { positive likelihood ratio. }\end{array}$} \\
\hline \multicolumn{5}{|c|}{ aExcluding patients with previously diagnosed COPD (FEV1/FVC) $<0.7}$. \\
\hline
\end{tabular}

height $\leq 4 \mathrm{~cm}$, but with $14 \%$ sensitivity and $96 \%$ specificity (Supplemental Table). These studies combined medical histories with physical examinations to enhance diagnostic usefulness, considerably increasing the positive likelihood ratio to 6.0. We combined the Lung Function Questionnaire with maximum laryngeal height, also obtaining a high positive likelihood ratio.

Agreeing with Kotz et al ${ }^{5}$ but in contrast to Price et $\mathrm{al}_{1}{ }^{6}$ we consider the COPD questionnaire unhelpful as a diagnostic tool but useful in ruling out COPD when score is $<19.5$. As did Hanania et al, ${ }_{1}^{7}$ we concluded that regarding its high sensitivity, the Lung Function Questionnaire could select for patients who should undergo spirometry testing

Our design overestimated our prevalence of COPD. We did not know the physiological variations by sex, race, and age, or in laryngeal height for different pathologic conditions and their relationship with bronchial obstruction. We assumed the single cutoff point used by other authors. ${ }^{8,9}$ An appropriate spectrum of disease should be used to extrapolate our findings.

The intrinsic validity of the Lung Function Questionnaire makes it useful for screening, but laryngeal height and the diagnostic questionnaire are
Function Questionnaire and

the laryngeal height is $\leq 4 \mathrm{~cm}$, and the Lung Function Questionnaire score is $\leq 18$, COPD probability increases to $96 \%$ (95\% CI, 86\%-99\%).

\section{DISCUSSION}

In our study, the prevalence of COPD and tobacco use was low, confirming territorial variability. ${ }^{11}$ There are few studies that describe laryngeal height with diagnostic value for COPD. ${ }^{8,9}$ The positive and negative likelihood ratios we found are very similar to those Strauss et a $1^{8,9}$ presented for maximum laryngeal not. Combining Lung Function Questionnaire and
laryngeal height can help to confirm or dismiss COPD

Although spirometry is still defined as an essential confirmatory test, ${ }^{1}$ every family physician might not have access to it. Spirometry is easily performed, but its technique requires training and experience for results to be reliable.

It would be useful to know the validity of easy questionnaires and physical examinations in primary care that would simplify a diagnosis of COPD. These tools could also facilitate the selection of patients who should undergo spirometry testing to confirm COPD. 
To read or post commentaries in response to this article, see it online at http://www.annfammed.org/content/13/1/49.

Key words: chronic obstructive pulmonary disease; COPD; laryngeal measurement; diagnostic questionnaire

Submitted July 20, 2014; submitted, revised, September 13, 2014; accepted October 6, 2014.

Author contributions: Verónica Casado, lead investigator, had full access to all the data in the study and takes responsibility for the integrity of the data and the accuracy of the data analysis; Esther Agustín, Martin N. Masdeu, and Andrés Alvarez performed spirometry; Mercedes Villafañe, Sofía Benéitez and Sandra Calvo administered the Lung Function Questionnaire; Tatiana Gonzalez and Héctor C. Martos made the laryngeal measurements; Merly Zelada and Beatriz Marcos administered the COPD diagnostic questionnaire; Ana Miranda, Sandra Navarro, Violeta Ramírez and Lorena San José assessed tobacco use; Natalia Santamarta and Natalia Spaans collected sociodemographic variables.

Acknowledgments: The authors thank Dr Juan Antonio Sánchez, Guillermo García, Ferran Cordón, Gemma Almonacid, and Noemí Rodriguez for their review of the text.

Additional information: This study, in its project stage, received the award for the best research project in the 2012 SocaleMFyC Research Conference.

Supplementary materials: Available at http://www.AnnFamMed. org/content/13/1/49/suppl/DC1/.

\section{References}

1. Global Strategy for the Diagnosis, Management and Prevention of COPD, Global Initiative for Chronic Obstructive Lung Disease (GOLD) http://www.goldcopd.org/uploads/users/files/GOLD_Report2014_ Feb07.pdf. Updated 2014. Accessed Jul 18, 2014.
2. Holleman D, Simel D. Does the clinical examination predict airflow limitation? JAMA. 1995;273(4):313-319.

3. Broekhuizen BD, Sachs A, Janssen $K$, et al. Does a decision aid help physicians to detect chronic obstructive pulmonary disease? Br J Gen Pract. 2011;61(591):e674-e679.

4. Broekhuizen BD, Sachs AP, Verheij TJ, et al. Accuracy of symptoms, signs, and C-reactive protein for early chronic obstructive pulmonary disease. Br J Gen Pract. 2012;62(602):e632-e638.

5. Kotz $D$, Nelemans $P$, van Schayck $C P$, Wesseling GJ. External validation of a COPD diagnostic questionnaire. Eur Respir J. 2008;31(2): 298-303.

6. Price DB, Tinkelman DG, Nordyke RJ, Isonaka S, Halbert RJ; COPD Questionnaire Study Group. Scoring system and clinical application of COPD diagnostic questionnaires. Chest. 2006;129(6):1531-1539.

7. Hanania NA, Mannino DM, Yawn BP, et al. Predicting risk of airflow obstruction in primary care: Validation of the Lung Function Questionnaire (LFQ). Respir Med. 2010;104(8):1160-1170.

8. Straus SE, McAlister FA, Sackett DL, Deeks JJ; CARE-COAD1 Group. The accuracy of patient history, wheezing, and laryngeal measurements in diagnosing obstructive airway disease. JAMA. 2000;283(14):1853-1857.

9. Straus SE, McAlister FA, Sackett DL, Deeks JJ; CARE-COAD2 Group. Accuracy of history, wheezing, and forced expiratory time in the diagnosis of chronic obstructive pulmonary disease. J Gen Intern Med. 2002;17(9):684-688.

10. Global strategy for diagnosis, management and prevention of COPD. Global Initiative for Chronic Obstructive Lung Disease (GOLD) 2014. http://www.goldcopd.org/.

11. Soriano JB, Miravitlles M, Borderías L, et al. is Diferencias geográficas en la prevalencia de EPOC en España: relación con hábito tabáquico, tasas de mortalidad y otros determinantes [Geographical variations in the prevalence of COPD in Spain: relationship to smoking, death rates and other determining factors] [in Spanish]. Arch Bronconeumol. 2010;46(10):522-530. 